\title{
A Serendipitously Discovered Facial Calcification- Case Report
}

\author{
Gargi S1*, Prasanna Kumar R², Raghavendra $\mathbf{K}^{3}$, Gowri Bhandarkar \\ $\mathrm{P}^{4}$, Roopashri Rajesh $\mathrm{K}^{4}$, Meghana $\mathrm{R}^{5}$, Ujwala $\mathrm{S}^{5}$ and Girish $\mathrm{YR}^{5}$ \\ ${ }^{1}$ Postgraduate Student, Department of Oral Medicine and Radiology, AJ Institute of \\ Dental Sciences, India
}

${ }^{2}$ Professor, Department of Oral Medicine and Radiology, AJ Institute of Dental

\begin{tabular}{|c|}
\hline Case Report \\
Volume 4 Issue 1 \\
Received Date: January 23, 2019 \\
Published Date: February 12, 2019 \\
D0I: 10.23880 /oajds-16000218 \\
\hline
\end{tabular}

Sciences, India

${ }^{3}$ Professor and Head, Department of Oral Medicine and Radiology, AJ Institute of Dental Sciences, India

${ }^{4}$ Reader, Department of Oral Medicine and Radiology, AJ Institute of Dental Sciences, India

${ }^{5}$ Assistant Professor, Department of Oral Medicine and Radiology, AJ Institute of Dental Sciences, India

*Corresponding author: Gargi Sengupta, Department of Oral Medicine and Radiology, AJ Institute of Dental Sciences, Kuntikana, Mangaluru, Karnataka, India, Tel: 9886891840; Email: gargisengupta2010@gmail.com

\begin{abstract}
Head and neck region are a relatively common location for soft tissues calcifications of various structures to occur in large population. They are one of the most common accidental finding during routine panoramic survey. Submandibular and cervical nodes are most commonly involved calcified nodes and are usually asymptomatic. Though identification might be difficult because of its close proximity to other structure in head and neck region. So practitioner must be aware of similar lesion occurring in this region from other radiopacities for differentiable diagnosis. Here we report a case of a multiple right submandibular and cervical lymph node calcification in 40 year old male patient which was an coincidental finding on panoramic radiograph.
\end{abstract}

Keywords: Facial Calcification; Cervical lymph node; Submandibular and cervical nodes

\section{Introduction}

Calcification is basically the accumulation of calcium salts in the body tissue .It normally occurs in the formation of bone, but its abnormal deposition can take place in soft tissues, causing it to harden. Heterotopic calcification is deposition of calcium salts, essentially calcium phosphate, in cluttered fashion in soft tissue [1]. It is divided into three categories: metastatic, idiopathic and dystrophic. The levels of serum calcium or phosphate increases, precipitation of minerals into normal tissue leads to metastatic calcification which spreads widely throughout the body comparatively to dystrophic calcifications which appears to be more localized, usually occurs bilaterally and symmetrically. Idiopathic calcification occurs in soft tissue inspite of having normal serum calcium and phosphate concentration among healthy tissues [2,3]. 


\section{Open Access Journal of Dental Sciences}

\section{Case Report}

A 40-year-old male presented to department of oral medicine and radiology with chief complaint of dull aching type of pain in relation to lower right and left back tooth region since twenty days, which aggrevated on having food and relived on medications (self medicationanalgesics). Patient had a history of infection at 3 years of his age on right side of face adjacent to preauricular region and underwent topical medication for it. He described it as small solitary nodule which was measuring about $1 \times 2 \mathrm{~cm}$ and within six months of medication it subsided. Non-contributory family history. He gave a history of arecanut chewing. On extraoral examination Scar seen in relation to right side of face, ellipsoidal shape which was extending superoinferiorly-from preauricular region till lower border of mandible (approx submandibular region) measuring about $3 \times 2 \mathrm{~cm}$, mediolaterally $-5 \mathrm{~cm}$ away from commissure of lip and $2 \mathrm{~cm}$ ahead of angle of mandible. Presence of mild pigmentation, slightly raised borders and depressed center, no induration, showed no signs of inflammation or secondary changes. Palpatory findings revealed raised edges with depressed center, measuring about $3 \times 2 \mathrm{~cm}$ irregular in texture, and pea shaped nodules measuring about $1 \mathrm{x} 1 \mathrm{~cm}$ in size, which were hard, non-compressible, non-fluctuant, non-tender with variable mobility (Figure 1).

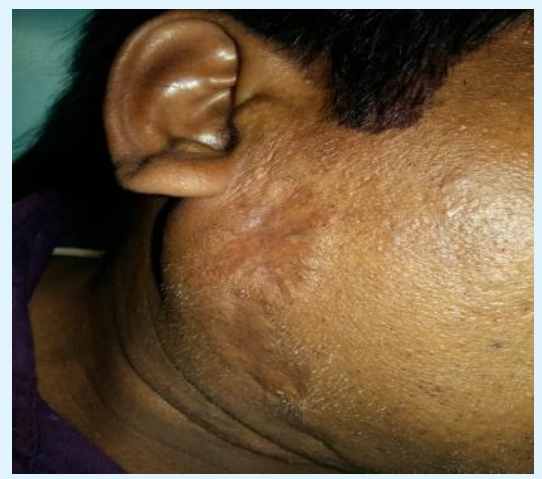

Figure 1: Scar seen on right side extending from preauricular region till submandibular region.

On intraoral hard tissue examination revealed presence of grade II mobility in relation to right and left lower posterior region pertaining to reported site. On local examination presence of discrete plaque like lesion bilaterally on labial vestibule\& buccal mucosa surrounded by erythematous erosive area, with angular whitish area in centre approximately of $2 \times 2.5 \mathrm{~cm}$, opposite premolar molar region and mild melanin pigmentation at periphery .On palpation lesion was non scrappable (Figures $2 \mathrm{~A}$ and B ), based on clinical presentation Scar secondary to previously infected area in relation to right preauricular region, submandibular region and bilateral lichenoid reaction.

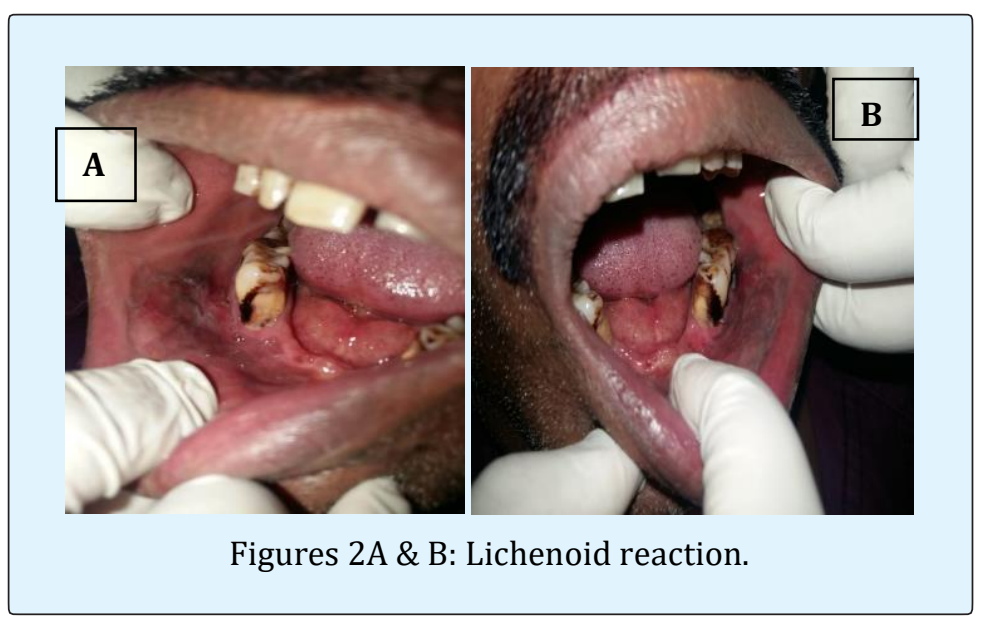

Panoramic radiograph taken for evaluating the reported site, revealed localised distribution of bone loss seen ranging from mild crestal bone resorption to severe extensive alveolar bone destruction extending from premolar to 2nd molar region bilaterally and unexpectedly revealed unilateral multiple radiopaque masses on right posterior border of ramus, below angle of mandible, $2 \mathrm{~cm}$ inferior to antegonial notch, and in cervical vertebrae area, with an ill-defined, irregularly shaped, heterogenous radiopacity. Presence of radiolucent serrations in radiopaque mass was noticed (Figure 3). To confirm with the location of radiopaque masses and for confirmatory purpose posterior anterior view (PA) was advised. PA - view revealed round radiopaque mass 


\section{Open Access Journal of Dental Sciences}

measuring around $1-3 \mathrm{~cm}$ in the right side of mandible pertaining to angle, posterior border of ramus, inferior to antegonial notch and in cervical vertebrae region (Figure 4). Based on history of infection pertaining to same site of incidental radiographic findings diagnosis of right submandibular and cervical lymph node calcification with differential diagnosis of sialolith, tonsilloliths, tuberculous lymph node calcification, phleboliths was given. As the patient was unaware of the condition, asymptomatic and incidentally found on radiograph, he denied for further investigations and treatment related to lymph node calcification.

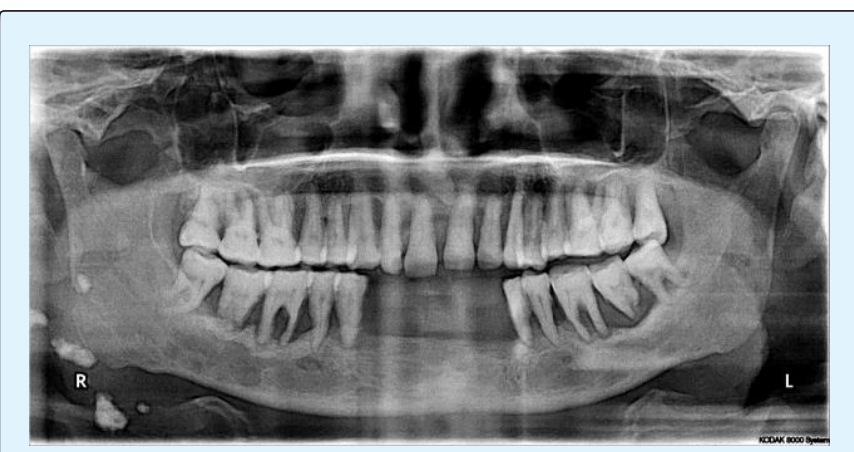

Figure 3: Panoramic radiographs showing unilateral radiopaque masses in posterior border of ramus, angle of mandible and inferior to antegonial notch.

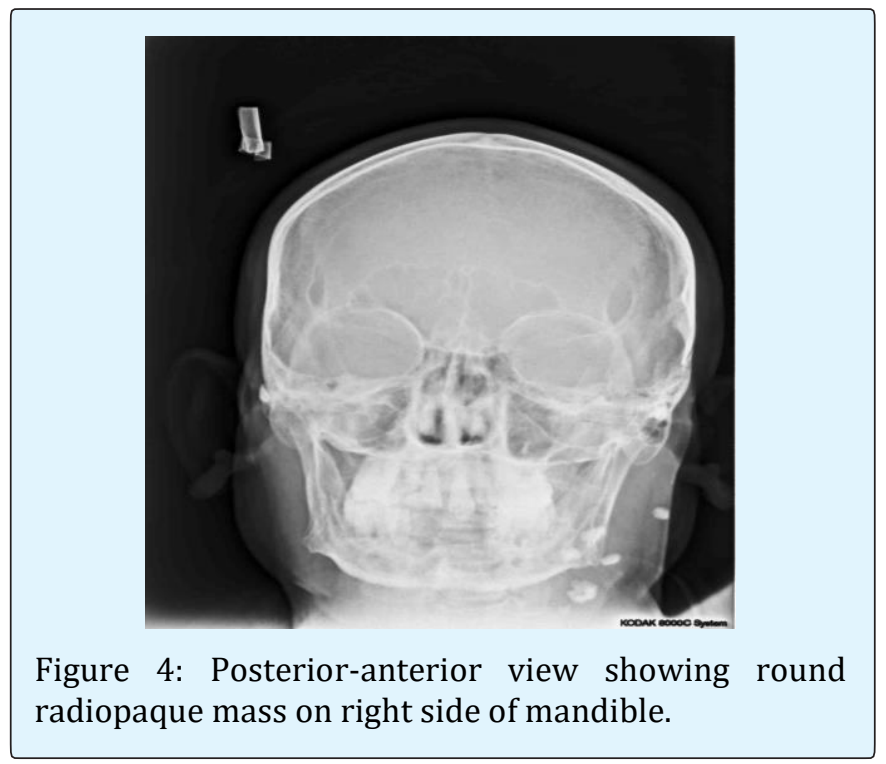

\section{Discussion}

Deposition of calcium specifically calcium phosphate salts leads to calcification and usually occurs in skeleton. When it occurs in disorganized pattern in soft tissues it's known as heterotopic calcification. Heterotopic Calcification is Classified into Three Categories:

a) Dystrophic: Deposition of mineral salts into primary site of chronic inflammation dead or degenerating tissues. Usually associated with high local concentration of phosphates as in normal bone calcification an increase in bone alkalinity .One of common location is a long standing chronically inflamed cyst [4].

b) Idiopathic: Deposition takes place despite of normal serum calcium concentration in healthy tissue, and as such cannot be classified as either dystrophic or metastatic. Examples of this are tumorous calcinosis which presents with calcifications around joints and calcinosis cutis, which manifests in the cutaneous or subcutaneous tissue overlying the jaw bones [3].

c) Metastatic calcification on the other hand results from higher than normal serum levels of calcium in normal tissue (e.g., hyperparathyroidism, hypercalcemia, of malignancy). Compared to dystrophic calcification they generally spread more widely throughout the body. They usually occurs bilaterally and symmetrically $[3,4]$.

Nodal calcifications in head and neck area are uncommon, about $1 \%$ of enlarged nodes. They usually expand during inflammatory processes. Eventually, the nodes become fibroid and its foci of calcification start to evolve. They are usually asymptomatic and they are often encountered as incidental findings on routine panoramic survey. The most commonly involved nodes are the submandibular, superficial and deep cervical lymph nodes $[1,5]$. Calcifications may affect a solitary node or a linear series of nodes, termed as lymph node "chaining" [6]. However studies have reported that less commonly involved are preauricular and submental areas making it rare [7]. Interestingly in present case one of calcification involving area is preauricular region which brings the need for reporting this case and to bring awareness of the same among dentists.

Calcification involving lymph nodes presents with variable characteristics features may be solitary or multiple, unilateral or bilateral, lying in approximately linear direction, and the boundary may be well defined and usually irregular, sometimes having a lobulated appearance resembling a cauliflower. Bony, hard, round or linear masses appears to be on palpatory findings with variable mobility, which was also recognized in present case [5].

The anatomic location, number, distribution, and pattern of the calcifications are important interpretative criteria in radiographic evaluation of soft tissue opacities [1]. Radiopacities presenting as an incidental finding in a 


\section{Open Access Journal of Dental Sciences}

soft tissue site during radiographic examination makes it mandatory to implement thorough clinical examination of the respective site, medical record. Radiographic evaluation also plays a pivotal role for differentiating such radioacities such as:

a) Anatomical position,

b) Number of radiopacities,

c) Shape \& size of the calcifications

d) Effect on surrounding and their internal structure which provides a guideline for their specific interpretation $[1,3]$.

Calcified lymph nodes were generally characterized by scars and swellings in neck area. They are usually asymptomatic unless it is secondarily infected. In present case patient presented with scar in the preauricular region which extended till submandibular region. Rarely, nodal calcification may be related with malignant diseases. These calcifications usually appear radiographically as a solitary round, oval, or linear calcified radiopaque masses with well-defined borders. One of the most common location is the submandibular region, either at or below the inferior border of the mandible near the angle, or between the posterior border of the ramus and cervical spine or sometimes overlaps the inferior aspect of the ramus and are thus misdiagnosed as osseous lesions [5]. Coincidentally, patient present calcified lymph nodes in similar location and also in rarest location according to literature in preauricular region which made it more interesting to be rare and reason to be reported.

So related to present case, location were calcification were observed mimicked calcifications like tonsilloliths, sialolith, foreign body ,ghost images, phleboliths. The differentiating features of silalolith from calcified lymph node is difficult as location were its projected is similar region on radiograph but characteristics feature of painful swelling and intensity of discomfort increasing during meal times and usually with a smooth outline makes it strongly indicative of sialolith. Similarly tonsillolith and phlebolith also sometimes found in similar location and can be misdiagnosed to be lymphnode calcification, but former is seen to be usually present as a cluster of multiple small radiopacities superimposed over the midramus region and later exhibit concentric calcific rings similar to the cross section of an onion [1,5,7]. Few more differentiating features based on location, clinical and radiographic findings (Table 1 ).

\begin{tabular}{|c|c|c|c|}
\hline Lesions & Age And Sex Predeliction & Location & Clinical And Radiographic Findings \\
\hline Sialoliths & $\begin{array}{l}\text { Any time from the } \\
\text { 1st decade of life on, with } \\
\text { the peak incidence } \\
\text { occurring between the 4th } \\
\text { and the 6th decades. } \\
\text { t } \quad \text { Males are affected } \\
\text { twice as often as females. }\end{array}$ & $\begin{array}{l}\text { Submandibular sialoliths: } \\
\text { - below body- and mesial } \\
\text { to angle of mandible, } \\
\text { - above hyoid bone or on } \\
\text { apices of mandibular premolars } \\
\text { Parotid sialoliths } \\
\text { - upper third of ramus or } \\
\text { anterior or posterior of it. }\end{array}$ & $\begin{array}{l}\text { Painful swelling, Smooth well defined } \\
\text { border. }\end{array}$ \\
\hline Tonsilloliths & $\begin{array}{l}-\quad \text { Range : } 10 \text { to } 77 \\
\text { years with a mean of } 50 \\
\text { years } \\
\text { - } \quad \text { Male/female ratio- } \\
1: 1\end{array}$ & $\begin{array}{l}\text { Mid portion of the mandibular } \\
\text { ramus in the region where the } \\
\text { image of the dorsal surface of } \\
\text { the tongue crosses the ramus in } \\
\text { the oropharyngeal air spaces. } \\
\text { Frequently appear on the } \\
\text { panoramic radiograph } \\
\text { immediately inferior to the } \\
\text { mandibular canal. }\end{array}$ & $\begin{array}{l}\text { - Pain and swelling, fetor oris, } \\
\text { dysphagia, or a foreign body } \\
\text { sensation on swallowing } \\
\text { - Multiple small, ill-defined } \\
\text { radiopacities. } \\
\text { - Rarely this calcification may } \\
\text { attain a large size. }\end{array}$ \\
\hline Phlebolith & No age and sex predeliction & $\begin{array}{l}\text { Lies in the identification of a } \\
\text { possible vascular lesion such as } \\
\text { a hemangioma. }\end{array}$ & $\begin{array}{l}\text { - Swollen, throbbing, or } \\
\text { discolored by the presence of veins or } \\
\text { a soft tissue hemangioma. } \\
\text { - Internal structure: may be } \\
\text { homogeneously radiopaque. } \\
\text { - More commonly has the } \\
\text { appearance of laminations, giving } \\
\text { phleboliths a bull's-eye or "target" } \\
\text { appearance. }\end{array}$ \\
\hline
\end{tabular}

Table 1: Differential Diagnosis. 


\section{Open Access Journal of Dental Sciences}

So detailed clinical examination, patient history and with appropriate imaging modalities is necessary to establish the final diagnosis. Panoramic or lateral oblique radiographs alone is difficult for relying for identification of soft tissue calcifications as both of them are 2D planar. Higher imaging modalities can be utilized for confirmatory diagnosis [5].

\section{Conclusion}

Even though cervical node calcification is an incidental finding on panoramic survey, but their detection is important to orient the diagnosis and prevention of diseases and may also assist the radiologist to help the referring dentist and patient in identifying the underlying systemic disease. Cervical node calcification may be associated with benign or malignant conditions and should be considered in the differential diagnosis of such lesions. Knowledge regarding anatomy of the maxillofacial region assists in determining the tissue origin .Clinical examination and medical history supports in eliminating unnecessary differential diagnosis thereby enhancing the radiographic diagnosis. Despite of low prevalence and relevance of these calcification in face and neck but when they are identified, the most common etiologies associated includes infection, inflammation and malignancy. Thus diagnosing and monitoring these conditions are essential for identification of more serious underlying disease. As diagnostician dealing with oral and maxillofacial region we shouldn't overlook the possibilities that may stimulate this phenomenon. The main differential diagnosis are foreign body, calcified lymph nodes, calcified parotid gland stones, tuberculous lymph nodes ,calcified vascular lesions, hemangioma, lymphangioma and lastly metastasis from distinct calcifying neoplasms.

\section{References}

1. Omami G (2016) Soft Tissue Calcification in Oral and Maxillofacial Imaging: A Pictorial Review. Int J Dentistry Oral Sci 3(4): 219-224.

2. Vengalath J, Puttabuddi JH, Rajkumar B, Shivakumar GC (2014) Prevalence of soft tissue calcifications on digital panoramic radiographs: A retrospective study. J Indian Acad Oral Med Radiol 26(4): 385-389.

3. Noffke C, Raubenheimer EJ, Chabikuli N (2015) Radiopacities in soft tissue on dental radiographs: diagnostic considerations. SADJ 70(2): 53-59.

4. Wells Adams B (2011) 1977 Incidence of soft tissue calcifications of the head and neck region on maxillofacial cone beam computed tomography. Electronic Theses and Dissertations Paper 1545.

5. Kamala KA (2017) Submandibular lymph node calcification-A Diagnostic dilemma. British Journal of Medical and Health Research 4(7).

6. Nedunchezhian K, Aswath N (2018) Radio-Diagnostic Dilemmas of Submandibular Calcification-An Incidental CBCT Finding. JCDR 12(9): 06-08.

7. Gunduz K, Canitezer G, Avsever H (2014) Tuberculous lymph node calcification detected on routine panoramic radiography: An unusual case. J Oral Maxillofac Radiol 2(2): 61-63. 